\title{
Understanding decreased fertility in women carriers of the FMR1 premutation: a possible mechanism for Fragile X-Associated Primary Ovarian Insufficiency (FXPOI)
}

\author{
Emmanuel Peprah
}

\begin{abstract}
Fragile $X$ syndrome (FXS) and its associated disorders are caused by the expansion of the CGG repeat in the $5^{\prime}$ untranslated region of the fragile $X$ mental retardation 1 gene (FMR1). The full mutation, defined as $>200$ cytosine-guanine-guanine (CGG) triplet repeats, causes FXS. Individuals with 55-199 CGG repeats, classified as premutation carriers, are affected by two distinct disorders depending on their premutation status. Disorders associated with premutation carriers include: Fragile X-associated Tremor Ataxia Syndrome (FXTAS) and Fragile X-associated Primary Ovarian Insufficiency (FXPOI). The molecular similarities of FXTAS and FXPOI (e.g. overabundance of FMR1 transcript and intranuclear inclusions) suggest that similar molecular mechanisms underlie both FXTAS and FXPOI. The current hypothesis describes the underlying mechanism for FXTAS as an mRNA gain-of-function mutation, however the underlying mechanism for FXPOI remains unresolved. New data suggests that repeat associated non-AUG (RAN) translation could underlie FXPOI.
\end{abstract}

Keywords: FXPOI, Ovarian insufficiency, FMR1, CGG repeat, Female reproductive health

\section{Background}

Fragile X Syndrome (FXS; OMIM 300624) is caused by hypermethylation of the expanded CGG repeats adjacent to exon 1 of the Fragile X Mental Retardation 1 gene (FMR1); this mutation affects $>98 \%$ of individuals with FXS [1-3]. The disorder affects $\sim 1 / 4000$ males and $\sim 1 /$ 8000 females in the general Caucasian population, with $\sim 60 \%$ of individuals with the full mutation also having autism spectrum disorders [3-6]. The expanded CGG repeats can be categorized as common, intermediate, premutation, and full mutation alleles. Common alleles found in the general population usually contain 6-40 CGG repeats which are stable and usually do not expand upon transmission from parent to offspring. Intermediate alleles containing 41-60 CGG repeats have variable expansion risks whereas premutation alleles (i.e. 55-199 CGG repeats) are usually unmethylated and can expand

Correspondence: peprahek@mail.nih.gov

National Institutes of Health, The Eunice Kennedy Shriver National Institute of Child Health and Human Development, 6100 Executive Blvd RM 5Z00, Rockville, MD 20852, USA to the full mutation (e.g. > 200 CGG repeats) upon transmission from parent to offspring [1,2]. In the full mutation, the expanded CGG repeat can be recognized as a $\mathrm{CpG}$ island resulting in methylation and transcriptional silencing of FMR1 [1,2,7]. Transcription silencing of FMR1 results in the loss of Fragile X Mental Retardation Protein (FMRP), which is necessary for neuronal development and cognition. FMR1 premutation carriers also have disorders associated with ovarian function including loss of fertility and hypoestrogenism (i.e., FXPOI) and neurodegeneration with associated memory loss and general Parkinsonism (i.e., FXTAS).

\section{FXPOI in female premutation carriers}

Before the discovery of FXPOI, the consequences of being a female premature carrier was ascribed to the risk of passing on a full mutation to offspring; the ovarian dysfunction reported by many carriers was underappreciated. It was not until others observed that premature ovarian failure, defined as menopause before the age of 40 , occurred in about $24 \%$ of FMR 1 premutation carriers 
compared to only $\sim 1 \%$ of all women in the general population that the scientific community started to closely examine the association between FMR1 and ovarian function [8-12]. Reports indicate that premutation alleles with 59 to 99 CGG repeats are associated with an increased risk of ovarian dysfunction in female carriers $[13,14]$. This positive linear association of repeat size with ovarian dysfunction seems to plateau or decrease for premutation carriers with $>100$ CGG repeats, however the exact threshold is currently unknown [15-19]. Furthermore, the linear association is not consistent because some intermediate repeats were associated with an increased risk for FXPOI compared to premutation repeats $>100[13,14]$. Additionally, the length of the CGG repeat contributes to the variation observed in age of ovarian dysfunction resulting in a loss of reproductive capacity; currently the threshold for the onset of FXPOI is ambiguous $[13,14,20]$. Because of these differences between menopause and fragile $\mathrm{x}$-associated ovarian insufficiency, the term "primary ovarian insufficiency" proposed by Welt and originally suggest by Albright compared to premature ovarian failure has been used to better describe the condition [21-23].

\section{Similarities of FXTAS and FXPOI}

The molecular mechanism underlying FXPOI is enigmatic but using RAN translation in FXTAS as a model could illuminate the disease biology of FXPOI. Similar to FXTAS, oocytes in FMR1 premutation ovarian insufficiency mouse models display aberrant accumulation of protein, elevated levels of ubiquitination which reports suggest are consistent with evidence of the FMR1 gainof-function mechanism hypothesized in FXTAS $[9,24]$. Todd and colleagues suggest that inclusion formation in FXTAS could be mediated by the translational byproducts of premutation alleles [25]. These aberrant FMRP by-products of non-AUG (RAN) translation, which have large glycine residues, mediate inclusion formation [25]. In fact, the mechanism was first reported by $\mathrm{Zu}$ and coworkers using spinocerebellar ataxia type 8 (SCA8) and myotonic dystrophy type 1 (DM1) as models to elucidate pathogenesis of triplet diseases [26]. Similar to other trinucleotide repeat expansion disorders (TNR), SCA8 and DM1 transcripts containing expanded cytosine-thymineguanine (CTG) repeats were translated via RAN. The translational by-products of CTG repeats resulted in the accumulation of aberrant proteins with large leucine polypeptide tracks [26]. Further analysis revealed that these RAN translational by-products resulted in significant pathology including neurodegeneration, a hallmark of TNR. Moreover, Todd and colleagues demonstrated that similar to SCA8 and DM1, expanded CGG repeats $(>90)$ were translated in Fragile X premutation carriers; the resulting translational products were high molecular weight FMRP with glycine residues, which the authors termed FMRpolyG [25]. FMRpolyG was shown to be important to inclusion formation and neurodegeneration, distinctive features of FXTAS and fully recapitulated the FXTAS phenotype [25].

\section{Conclusion and perspective}

The lucidity of the molecular mechanism of FXTAS is emerging, however the pathobiology of FXPOI is opaque [27]. This would suggest that greater effort is needed to elucidate the underlying mechanisms of FXPOI via animal models and clinical studies using appropriate populations. Likewise, mice and other animal models could present opportunities to determine whether there are threshold effects for CGG repeat length in FXPOI and infer the biological mechanism. Namely, only a subset of premutation carriers develop FXPOI; one case report described premutation monozygotic twins discordant for the FXPOI phenotype although the X-inactivation ratios were similar for both sisters [28]. This is a very fascinating case report, and determining the genetic context of the premutation alleles by examining genetic elements (e.g., SNPS, CNVs) on the X chromosome (and if possible sequence their genomes) to determine the genetics associated with this is very compelling.

Finally, characterizing RAN translation by-products in animal models of FXPOI could provide the molecular evidence to understanding ovarian ageing associated with FMR1. Regardless, Todd and colleagues have shown that the RAN translation mechanism of premutation CGG repeats produces aberrant proteins essential for inclusion formation, resulting in FXTAS pathology. In FXPOI, RAN translation could occur in ovaries, granulosa cells, and/or other cell types. Given that inclusion formation has been found in several tissues of individuals with FXTAS, it is reasonable to assume that these inclusions exist in FXPOI. Confirmation of the importance of RAN translation byproducts to FXPOI will significantly increase our understanding of the disorder and could provide an avenue to understanding ovarian dysfunction in FMR1 premutation carriers.

\section{Abbreviations \\ CNV: Copy number variation; FMR1: Fragile X mental retardation 1 gene (FMR1); FXTAS: Fragile X-associated tremor ataxia syndrome (FXTAS); FXPOI: Fragile $X$-associated primary ovarian insufficiency (FXPOI); RAN: Repeat associated non-AUG (RAN) translation; SNP: Single nucleotide polymorphisms; TNR: Trinucleotide repeat expansion disorders.}

\section{Competing interests}

The author declares he has no other competing interests.

\section{Acknowledgements}

This publication was supported by the Eunice Kennedy Shriver National Institute of Child Health and Human Development of the National Institutes of Health. The content is solely the responsibility of the author and does not necessarily represent the official views of the National Institutes of Health. 
Received: 9 April 2014 Accepted: 13 August 2014

Published: 19 August 2014

\section{References}

1. Fu Y, Kuhl D, Pizzuti A, Pieretti M, Sutcliffe J, Richards S, Verkerk A, Holden J, Fenwick $R$, Warren S: Variation of the CGG repeat at the Fragile $X$ site results in gene instability: resolution of the Sherman paradox. Cell 1991, 67:1047-1058.

2. Verkerk A, Pieretti M, Sutcliffe J, Fu Y, Pizzuti A, Reiner O, Richards S, Victoria $M$, Zhang F: Identification of a gene (FMR-1) containing a CGG repeat coincident with a breakpoint cluster region exhibiting length variation in Fragile X syndrome. Cell 1991, 65:905-914.

3. Crawford D, Acuna J, Sherman S: FMR1 and the Fragile $X$ syndrome: human genome epidemiology review. Genet Med 2001, 3(5):359-371

4. Garber K, Smith K, Reines D, Warren S: Transcription, translation and Fragile X Syndrome. Curr Opin Genet Dev 2006, 16:270-275.

5. Goodlin-Jones BL, Tassone F, Gane LW: Autistic spectrum disorder and the fragile X premutation. J Dev Behav Pediatr 2004, 25(6):392-398.

6. Budimirovic DB, Kaufmann WE: What can we learn about autism from studying fragile X syndrome? Dev Neurosci 2011, 33(5):379-394.

7. Sutcliffe J, Nelson D, Zhang F, Pieretti M, Caskey T, Saxe D, Warren S: DNA methylation represses FMR-1 transcription in fragile $\mathrm{X}$ syndrome. Hum Mol Genet 1992, 1:397-400.

8. Coulam CB: Premature gonadal failure. Fertil Steril 1982, 38(6):645-655.

9. Lu CL, Lin L, Tan HP, Wu H, Sherman SL, Gao F, Jin P, Chen DH: Fragile $X$ premutation RNA is sufficient to cause primary ovarian insufficiency in mice. Hum Mol Genet 2012, 21(23):5039-5047.

10. Woad KJ, Watkins WJ, Prendergast D, Shelling AN: The genetic basis of premature ovarian failure. Aust N Z J Obstet Gynaecol 2006, 46(3):242-244.

11. Allingham-Hawkins SJ, Babul-Hirji R, Chitayat D, Holden JJA, Yang KT, Lee C, Hudson R, Gorwill H, Nolin SL, Glicksman A, Jenkins E, Brown WT, HowardPeebles PN, Becchi C, Cummings E, Fallon L, Seitz S, Black SH, ViannaMorgante AM, Costa SS, Otto PA, Mingroni-Netto RC, Murray A, Webb J, MacSwinney F, Dennis N, Jacobs PA, Syrrou M, Georgiou I, Patsalis PC, et al: Fragile $\mathrm{X}$ premutation is a significant risk factor for premature ovarian failure: The international collaborative POF in fragile $X$ study - Preliminary data. Am J Med Genet 1999, 83(4):322-325

12. Wittenberger MD, Hagerman RJ, Sherman SL, McConkie-Rosell A, Welt CK, Rebar RW, Corrigan EC, Simpson JL, Nelson LM: The FMR1 premutation and reproduction. Fertil Steril 2007, 87(3):456-465.

13. Bretherick K, Fluker M, Robinson W: FMR1 repeat sizes in the gray zone and high end of the normal range are associated with premature ovarian failure. Hum Genet 2005, 117:376-382

14. Bodega B, Bione S, Toniolo L, Ornaghi F, Vegetti W, Ginelli E, Marozzi A: Influence of intermediate and uninterrupted FMR1 CGG expansions in premature ovarian failure manifestation. Hum Reprod 2006, 21(4):952-957.

15. Oostra BA, Willemsen R: A fragile balance: FMR1 expression levels. Hum Mol Genet 2003, 12(Spec No 2):R249-R257.

16. Welt $C$, Smith $P$, Taylor A: Evidence of early ovarian aging in Fragile $X$ Premutation carriers. J Clin Endocrinol Metab 2004, 89(9):4569-4574.

17. Sullivan AK, Crawford DC, Scott EH, Leslie ML, Sherman SL: Paternally transmitted FMR1 alleles are less stable than maternally transmitted alleles in the common and intermediate size range. Am J Hum Genet 2002, 70(6):1532-1544.

18. Sullivan A, Marcus M, Epstein M, Allen E, Anido A, Paquin J, Yadav-Shah M, Sherman S: Association of FMR1 repeat size with ovarian dysfunction. Hum Reprod 2005, 20(2):402-412.

19. Ennis S, Ward D, Murray A: Nonlinear association between CGG repeat number and age of menopause in FMR1 premutation carriers. Eur J Hum Genetics 2005, 14:253-255.

20. Voorhuis M, Onland-Moret NC, Fauser BC, van Amstel HK P, van der Schouw $Y T$, Broekmans FJ: The association of CGG repeats in the FMR1 gene and timing of natural menopause. Hum Reprod 2013, 28(2):496-501.

21. Welt CK: Primary ovarian insufficiency: a more accurate term for premature ovarian failure. Clin Endocrinol 2008, 68(4):499-509.

22. Nelson LM: Clinical practice. Primary ovarian insufficiency. N Engl J Med 2009, 360(6):606-614.

23. Albricht $\mathrm{H}$, Smith $\mathrm{PH}$, Fraser R: A syndrome characterized by primary ovarian insufficiency and decreased stature - Report of 11 cases with a digression on hormonal control of axillary and pubic hair. Am J Med SCi 1942, 204(5):625-648.
24. Hoffman GE, Le WW, Entezam A, Otsuka N, Tong ZB, Nelson L, Flaws JA, McDonald JH, Jafar S, Usdin K: Ovarian abnormalities in a mouse model of fragile X primary ovarian insufficiency. J Histochem Cytochem 2012, 60(6):439-456

25. Todd PK, Oh SY, Krans A, He F, Sellier C, Frazer M, Renoux AJ, Chen KC, Scaglione KM, Basrur V, Elenitoba-Johnson K, Vonsattel JP, Louis ED, Sutton MA, Taylor JP, Mills RE, Charlet-Berguerand N, Paulson HL: CGG repeatassociated translation mediates neurodegeneration in fragile $\mathrm{X}$ tremor ataxia syndrome. Neuron 2013, 78(3):440-455.

26. Zu T, Gibbens B, Doty NS, Gomes-Pereira M, Huguet A, Stone MD, Margolis J, Peterson M, Markowski TW, Ingram MA, Nan Z, Forster C, Low WC, Schoser B, Somia NV, Clark HB, Schmechel S, Bitterman PB, Gourdon G, Swanson MS, Moseley M, Ranum LP: Non-ATG-initiated translation directed by microsatellite expansions. Proc Natl Acad Sci U S A 2011, 108(1):260-265.

27. Cooper AR, Baker VL, Sterling EW, Ryan ME, Woodruff TK, Nelson LM: The time is now for a new approach to primary ovarian insufficiency. Fertil Steril 2011, 95(6):1890-1897.

28. Johnston-MacAnanny EB, Koty P, Pettenati M, Brady M, Yalcinkaya TM, Schmidt DW: The first case described: monozygotic twin sisters with the fragile $X$ premutation but with a different phenotype for premature ovarian failure. Fertil Steril 2011, 95(7):2431 e2413-2435.

doi:10.1186/1742-4755-11-67

Cite this article as: Peprah: Understanding decreased fertility in women carriers of the FMR1 premutation: a possible mechanism for Fragile X-Associated Primary Ovarian Insufficiency (FXPOI). Reproductive Health 2014 11:67.

\section{Submit your next manuscript to BioMed Central and take full advantage of:}

- Convenient online submission

- Thorough peer review

- No space constraints or color figure charges

- Immediate publication on acceptance

- Inclusion in PubMed, CAS, Scopus and Google Scholar

- Research which is freely available for redistribution 